\title{
Risk factors associated with functional dyspepsia in Chinese children: a cross-sectional study
}

Zhongcao Wei ${ }^{1}$, Xing Yang ${ }^{2}$, Xin Xing ${ }^{3}$, Lei Dong ${ }^{1}$, Jinhai Wang ${ }^{1 *}$ and Bin Qin ${ }^{1 *}$

\begin{abstract}
Background: There is no study assessing the risk factors associated with functional dyspepsia (FD) in Chinese children based on the Rome IV criteria.

Methods: In this cross-sectional study, we analyzed data from eight representative primary and secondary schools to assess the risk factors associated with FD in Chinese children based on the Rome IV criteria.

Results: A total of 6976 Chinese children were enrolled. The mean age was $14.3 \pm 2.5$ years, with a range from 7 to 17 years, and 3497 (50.1\%) participants were female. FD was prevalent in 209 (3.0\%) of the Chinese child population studied. Age $(O R=1.112, P=0.006)$, living independent of parents $(O R=1.677, P<0.001)$, prolonged school meals $(\mathrm{OR}=2.107, P<0.001)$, never eat breakfast $(\mathrm{OR}=2.192, P=0.003)$, often/daily eat cold foods $(\mathrm{OR}=2.296, P=0.002$; $\mathrm{OR}=2.736, P=0.011)$, and often eat pickled foods $(\mathrm{OR}=2.390, P=0.001)$ were found to be independent risk factors for FD. A nomogram with these risk factors had good discrimination (AUC $=0.727$ ) and calibration (Hosmer-Lemeshow test was 0.851).
\end{abstract}

Conclusions: Age, living independent of parents, prolonged school meals, never eat breakfast, often/daily eat cold foods and often eat pickled foods were independent risk factors for FD. The nomogram could be used as a quick screening tool to assess FD in Chinese children.

Keywords: Functional dyspepsia, Risk factors, Chinese children, Rome IV

\section{Background}

Functional dyspepsia (FD) is a gastrointestinal (GI) disorder syndrome characterized by symptoms such as abdominal pain, epigastric burning, postprandial fullness or early satiation [1-3]. The prevalence of FD has been estimated to range from $<2 \%$ to $57 \%$ in the general worldwide population [4-7]. Although FD is rarely fatal, it is associated with a significant reduction in the quality of life, has a significant, negative impact on work efficiency

\footnotetext{
*Correspondence: jinhaiwang@hotmail.com; qinbin16@163.com ${ }^{1}$ Department of Gastroenterology, The Second Affiliated Hospital, Xi'an Jiaotong University, Xi'an, Shaanxi, China

Full list of author information is available at the end of the article
}

and increases medical costs for the patient and society [8-10].

Current treatments for FD are unsatisfactory for both physicians and patients, and few treatment options have been shown to be effective against FD thus far [11, 12]. Many FD patients report that dyspeptic symptoms are associated with dietary habits. Diet-related risk factors in populations with FD have been largely unexplored [13, 14]. There is a lack of relevant research data in the Chinese population, and risk factors in the Chinese population need further study.

The diagnosis of FD is clinical and based on the Rome criteria. The Rome IV criteria were introduced in 2016 as an update of the Rome III criteria $[15,16]$. For children, 
the Rome IV criteria have been modified in terms of the time required to diagnose FD (at least four days a month) and in the established subcategories (dividing FD into postprandial distress syndrome and epigastric pain syndrome) [17, 18]. There have been few studies assessing FD based on the Rome IV criteria, especially among Chinese children; hence, further studies assessing FD based on the Rome IV criteria are urgently needed.

Understanding the risk factors of FD on the basis of Rome IV criteria will contribute to the diagnosis and prevention of FD. The aim of this study was to assess the diet-related risk factors associated with FD based on the Rome IV criteria and to identify other risk factors associated with FD in Chinese children.

\section{Methods}

\section{Study design}

This cross-sectional study was conducted at eight representative primary and secondary schools to assess the risk factors associated with FD in Chinese children based on the Rome IV criteria in Shaanxi province, China, from March 2017 to September 2017. All procedures were conducted in accordance with the relevant guidelines and regulations. Patients who met the inclusion and exclusion criteria were included in the analysis. The inclusion criteria included all children (ages 7 to 17 years) in each school. And the exclusion criteria were not willing to participate in the study, age $\geq 18$ years or incomplete data. Written informed consent was obtained from school administrators and the participating children prior to the survey. This study was approved by the Ethics Committee of the Second Affiliated Hospital of Xi'an Jiaotong University.

\section{Sample size calculation}

Sample size calculation was based on point that the prevalence of FD has been estimated to range from $<2$ to $57 \%$ in the general worldwide population [4-7].

We selected the lower incidence rate of $3 \%$ as the reference standard, with a $0.6 \%$ margin of error and $95 \%$ confidence level. The sample size calculated by the PASS 15.0 software was 3277 . Assuming that the pass rate of the questionnaire is $80 \%$, at least 3933 children needed to be screened for this study.

\section{Data collection}

All related data were collected through questionnaires according to the Rome IV criteria. Face-to-face interviews were conducted with all participating children, and all the interviews were carried out by trained field investigators. Basic demographic data included name, gender, age, height, and weight, height and weight were used to calculate the body mass index (BMI). We also collected growth history (history of breastfeeding, living independent of parents, long school accommodations (school accommodations $\geq$ five days per week) and prolonged school meals (school meals $\geq$ five days per week)), dyspeptic information (dyspeptic symptoms, symptom durations, symptom frequencies and the relationship with defecation) and dietary habits (breakfast, staple foods, cold foods, spicy foods, milk products, carbonated beverages, high-fiber foods, fried foods, salty foods, desserts, highly starchy foods, fruits, vegetables). The dietary frequency was divided into never, occasionally (1-2 times per week), sometimes (3-4 times per week), often (more than 5 times a week, but not every day), and daily [19]. And each question was explained to the participating children in detail to help them understand by the investigators.

\section{Definition of FD}

The presence or absence of FD was determined by the questionnaire according to the Rome IV criteria. FD was defined as at least one of postprandial fullness, early satiety, epigastric pain or epigastric burning that occurred for at least 2 months and at least 4 days in each month. Epigastric pain syndrome (EPS) was defined as at least one of epigastric pain or epigastric burning that occurred for at least 2 months and at least 4 days in each month. Postprandial distress syndrome (PDS) was defined as at least one of postprandial fullness or early satiety that occurred for at least 2 months and at least 4 days in each month.

\section{Statistical analysis}

Statistical analyses were conducted using SPSS 20.0 software (IBM Corp., Armonk, New York, USA) and $\mathrm{R}$ software (version 4.0.1). Categorical variables are reported as counts and percentages and were evaluated using chi-square tests or Fisher's exact test when appropriate. Continuous variables are reported as the means \pm SDs and were evaluated using a $t$ test or the Kruskal-Wallis test when appropriate. All variables were explored by univariate analysis, and variables with $P$ values $<0.10$ in univariate analysis were entered into the multivariate logistic regression analysis. Data were expressed as ORs and 95\% confidence intervals (CIs). Statistical significance was defined as $P<0.05$. A nomogram was constructed based on the logistic regression results. The discrimination was evaluated using the area under receiver operating characteristic (ROC) curve, and calibration was evaluated using the calibration curve and the Hosmer-Lemeshow test. 


\section{Results}

\section{Baseline of patient characteristics}

We screened 8878 students from eight primary and secondary schools; after excluding 1902 students due to decline to participate or age $\geq 18$ years or incomplete data, a total of 6976 school students were included in the final analysis, including 209 with FD and 6767 without. The flowchart of the study is shown in Fig. 1. The mean age was $14.3 \pm 2.5$ years, with a range from 7 to 17 years, and 3497 (50.1\%) participants were female. The majority of the population 5978 (85.7\%) had a history of breastfeeding, and a total of 2773 (39.8\%) lived independent of parents. In all, 3315 (47.5\%) children had long school accommodations, and 3881 (55.6\%) had prolonged school meals (Table 1).

\section{Prevalence of FD in children}

FD, according to the Rome IV criteria, was prevalent in 209 (3.0\%) of the Chinese child population studied. Among the 209 children with FD, the mean age was $15.3 \pm 2.1$ years, and $117(56.0 \%)$ of the sufferers were female. Among the children with FD according to the Rome IV criteria, 40 children only presented with EPS, 146 children only met the criteria for PDS, and 23 children presented with both EPS and PDS. The symptom subtypes of FD in this population are shown in Fig. 2.

\section{Risk factors for FD in children}

Comparisons of various factors between the children with FD and those without (Table 1). In univariate analysis, there were statistically significant differences between FD and no FD in age, living independent of parents, long school accommodation, prolonged school meals, staple foods, breakfast, cold foods, spicy foods, high-fiber

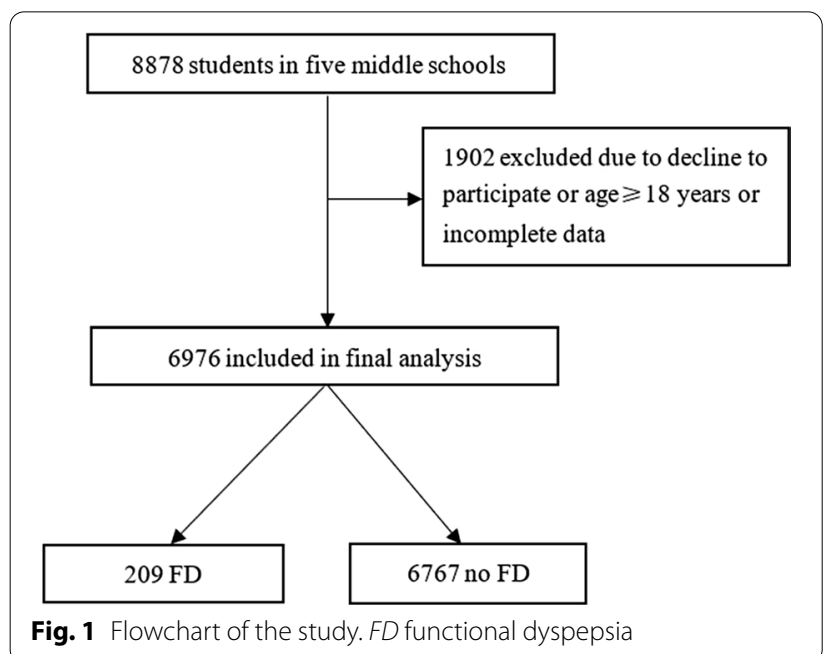

foods, fried foods, pickled foods $(P<0.001)$, and desserts $(P=0.013)$.

The independent risk factors for FD in Chinese children were explored by a multivariate logistic regression analysis. Any variables with $P$ values $<0.10$ in the univariate analysis were incorporated into multivariate analysis. In the multivariate logistic regression analysis, BMI, gender, fruits, vegetables were analyzed together with age, living independent of parents, long school accommodations, prolonged school meals, staple foods, breakfast, cold foods, spicy foods, high-fiber foods, fried foods, pickled foods, desserts. Age $(\mathrm{OR}=1.112,95 \% \mathrm{CI}=1.031-1.201$, $P=0.006)$, living independent of parents ( $\mathrm{OR}=1.677$, $95 \% \mathrm{CI}=1.255-2.242, P<0.001)$, prolonged school meals $(\mathrm{OR}=2.107,95 \% \mathrm{CI}=1.447-3.068, P<0.001)$, never eat breakfast $(\mathrm{OR}=2.192,95 \% \mathrm{CI}=1.103-3.688, P=0.003)$, often/daily eat cold foods $(\mathrm{OR}=2.296,95 \% \mathrm{CI}=1.347-$ 3.912, $P=0.002 ; \quad \mathrm{OR}=2.736, \quad 95 \% \quad \mathrm{CI}=1.263-5.927$, $P=0.011)$, and often eat pickled foods $(\mathrm{OR}=2.390,95 \%$ $\mathrm{CI}=1.435-3.981, P=0.001)$ were discovered to be the independent risk factors for FD (Table 1).

\section{Creation of the nomogram}

Based on the independent risk factors of FD, a nomogram was established (Fig. 3). The variables independently associated with FD and included in the final nomogram were age, living independent of parents, prolonged school meals, breakfast, cold foods, pickled foods. At the top of the nomogram was a reference line that represented the score from 0 to 100 for each variable. By summing the total score of each predictor, the probability of FD could be estimated effectively. The predictive value of the nomogram was assessed by the ROC curve, calibration curve and Hosmer-Lemeshow test. The area under the curve (AUC) was 0.727 , showed good discrimination (Fig. 4). The calibration curve was close to the diagonal line (Fig. 5) and the Hosmer-Lemeshow test was $0.851>0.05$, showing good calibration.

\section{Discussion}

As far as we know, this study was the first study to assess the risk factors associated with FD in Chinese children based on the Rome IV criteria. As FD is considered a chronic recurrent disease and has seriously reduced the quality of life and significantly increased healthcare costs, studies have focused on searching for the causes of and treatment methods for FD [20-22]. In this cross-sectional study, we assessed the diet-related risk factors and other risk factors associated with FD based on the Rome IV criteria, and found that age, living independent of parents, prolonged school meals, never eat breakfast, often/ daily eat cold foods, and often eat pickled foods were independent risk factors for FD. Moreover, we developed 
Table 1 Univariate and multivariate analyses of functional dyspepsia (FD) and no FD

\begin{tabular}{|c|c|c|c|c|c|c|}
\hline \multirow[t]{2}{*}{ Characteristics } & \multirow[t]{2}{*}{ No FD $(n=6767)$} & \multirow[t]{2}{*}{$\mathrm{FD}(\mathrm{n}=209)$} & \multirow[t]{2}{*}{$P$ value $^{\mathrm{a}}$} & \multicolumn{3}{|c|}{ Multivariate analyses } \\
\hline & & & & OR & $95 \% \mathrm{Cl}$ & $P$ value ${ }^{b}$ \\
\hline Age & $14.3 \pm 2.5$ & $15.3 \pm 2.1$ & $<0.001$ & 1.112 & $1.031-1.201$ & 0.006 \\
\hline BMl & $19.9 \pm 3.7$ & $20.1 \pm 3.4$ & 0.054 & & & \\
\hline Sex & & & 0.086 & & & \\
\hline Male & $3387(50.1)$ & $92(44.0)$ & & & & \\
\hline Female & 3380 (49.9) & $117(56.0)$ & & & & \\
\hline History of breastfeeding & & & 0.825 & & & \\
\hline Yes & $5800(85.7)$ & $178(85.2)$ & & & & \\
\hline No & $967(14.3)$ & $31(14.8)$ & & & & \\
\hline Living independent of parents & & & $<0.001$ & & & \\
\hline Yes & $2650(39.2)$ & $123(58.9)$ & & 1.677 & $1.255-2.242$ & $<0.001$ \\
\hline No & $4117(60.8)$ & $86(41.1)$ & & 1.00 & & \\
\hline Long school accommodation & & & $<0.001$ & & & \\
\hline Yes & $3166(46.8)$ & $149(71.3)$ & & & & \\
\hline No & $3601(53.2)$ & $60(28.7)$ & & & & \\
\hline Prolonged school meals & & & $<0.001$ & & & \\
\hline Yes & $3715(54.9)$ & $166(79.4)$ & & 2.107 & $1.447-3.068$ & $<0.001$ \\
\hline No & $3052(45.1)$ & $43(20.6)$ & & 1.00 & & \\
\hline Staple foods & & & $<0.001$ & & & \\
\hline Mainly noodles & $679(10.0)$ & $19(9.1)$ & & & & \\
\hline Mainly rice & $1743(25.8)$ & 78 (37.3) & & & & \\
\hline Rarely eat & $299(4.4)$ & $15(7.2)$ & & & & \\
\hline Both & 4046 (59.8) & $97(46.4)$ & & & & \\
\hline Breakfast & & & $<0.001$ & & & 0.005 \\
\hline Never & $262(3.9)$ & $23(11.0)$ & & 2.192 & $1.303-3.688$ & 0.003 \\
\hline Occasionally & 1139 (16.8) & 43 (20.6) & & 1.014 & $0.671-1.530$ & 0.948 \\
\hline Sometimes & 864 (12.8) & $31(14.8)$ & & 1.065 & $0.679-1.673$ & 0.783 \\
\hline Often & 2190 (32.4) & $53(25.4)$ & & 0.783 & $0.535-1.148$ & 0.211 \\
\hline Daily & $2312(34.2)$ & $59(28.2)$ & & 1.00 & & \\
\hline Cold foods & & & $<0.001$ & & & $<0.001$ \\
\hline Never & $1038(15.3)$ & $26(12.4)$ & & 1.00 & & \\
\hline Occasionally & 3606 (53.3) & $84(40.2)$ & & 0.866 & $0.549-1.367$ & 0.538 \\
\hline Sometimes & $1543(22.8)$ & $47(22.5)$ & & 1.019 & $0.615-1.688$ & 0.942 \\
\hline Often & $467(6.9)$ & 40 (19.1) & & 2.296 & $1.347-3.912$ & 0.002 \\
\hline Daily & $113(1.7)$ & $12(5.7)$ & & 2.736 & $1.263-5.927$ & 0.011 \\
\hline Spicy foods & & & $<0.001$ & & & \\
\hline Never & 1187 (17.5) & $34(16.3)$ & & & & \\
\hline Occasionally & 3244 (47.9) & $86(41.1)$ & & & & \\
\hline Sometimes & 1731 (25.6) & $50(23.9)$ & & & & \\
\hline Often & $502(7.4)$ & $32(15.3)$ & & & & \\
\hline Daily & $103(1.5)$ & $7(3.3)$ & & & & \\
\hline Milk products & & & 0.250 & & & \\
\hline Never & $390(5.8)$ & $17(8.1)$ & & & & \\
\hline Occasionally & 1243 (18.4) & $30(14.4)$ & & & & \\
\hline Sometimes & 1733 (25.6) & $53(25.4)$ & & & & \\
\hline Often & 1913 (28.3) & $55(26.3)$ & & & & \\
\hline Daily & $1488(22.0)$ & $54(25.8)$ & & & & \\
\hline Carbonate beverages & & & 0.753 & & & \\
\hline Never & $1761(26.0)$ & $53(25.4)$ & & & & \\
\hline
\end{tabular}


Table 1 (continued)

\begin{tabular}{|c|c|c|c|c|c|c|}
\hline \multirow[t]{2}{*}{ Characteristics } & \multirow[t]{2}{*}{ No FD $(n=6767)$} & \multirow[t]{2}{*}{$\mathrm{FD}(\mathrm{n}=209)$} & \multirow[t]{2}{*}{$P$ value ${ }^{a}$} & \multicolumn{3}{|c|}{ Multivariate analyses } \\
\hline & & & & OR & $95 \% \mathrm{Cl}$ & $P$ value $^{\mathrm{b}}$ \\
\hline Occasionally & 2815 (41.6) & $83(39.7)$ & & & & \\
\hline Sometimes & 1339 (19.8) & $40(19.1)$ & & & & \\
\hline Often & $653(9.6)$ & $25(12.0)$ & & & & \\
\hline Daily & $199(2.9)$ & $8(3.8)$ & & & & \\
\hline High-fiber foods & & & 0.019 & & & \\
\hline Never & $1196(17.7)$ & $46(22.0)$ & & & & \\
\hline Occasionally & $2360(34.9)$ & $88(42.1)$ & & & & \\
\hline Sometimes & $1835(27.1)$ & $40(19.1)$ & & & & \\
\hline Often & $981(14.5)$ & $27(12.9)$ & & & & \\
\hline Daily & $395(5.8)$ & $8(3.8)$ & & & & \\
\hline Fried foods & & & $<0.001$ & & & \\
\hline Never & $1020(15.1)$ & $30(14.4)$ & & & & \\
\hline Occasionally & $3120(46.1)$ & $65(31.1)$ & & & & \\
\hline Sometimes & $1765(26.1)$ & $63(30.1)$ & & & & \\
\hline Often & $688(10.2)$ & $38(18.2)$ & & & & \\
\hline Daily & $174(2.6)$ & $13(6.2)$ & & & & \\
\hline Pickled foods (n, \%) & & & $<0.001$ & & & 0.010 \\
\hline Never & $2382(35.2)$ & $63(30.1)$ & & 1.00 & & \\
\hline Occasionally & 2864 (42.3) & $80(38.3)$ & & 1.032 & $0.731-1.456$ & 0.860 \\
\hline Sometimes & $1134(16.8)$ & $36(17.2)$ & & 1.018 & $0.660-1.571$ & 0.935 \\
\hline Often & $312(4.6)$ & $25(12.0)$ & & 2.390 & $1.435-3.981$ & 0.001 \\
\hline Daily & $75(1.1)$ & $5(2.4)$ & & 1.368 & $0.485-3.859$ & 0.553 \\
\hline Dessert (n, \%) & & & 0.013 & & & \\
\hline Never & 788 (11.6) & $17(8.1)$ & & & & \\
\hline Occasionally & $2542(37.6)$ & $68(32.5)$ & & & & \\
\hline Sometimes & $1918(28.3)$ & $57(27.3)$ & & & & \\
\hline Often & $1150(17.0)$ & $48(23.0)$ & & & & \\
\hline Daily & $369(5.5)$ & $19(9.1)$ & & & & \\
\hline High starchy foods (n, \%) & & & 0.215 & & & \\
\hline Never & $432(6.4)$ & $20(9.6)$ & & & & \\
\hline Occasionally & $1503(22.2)$ & $48(23.0)$ & & & & \\
\hline Sometimes & $2284(33.8)$ & $58(27.8)$ & & & & \\
\hline Often & $1791(26.5)$ & $60(28.7)$ & & & & \\
\hline Daily & $757(11.2)$ & $23(11.0)$ & & & & \\
\hline Fruits (n, \%) & & & 0.068 & & & \\
\hline Never & $199(2.9)$ & $11(5.3)$ & & & & \\
\hline Occasionally & $1135(16.8)$ & $46(22.0)$ & & & & \\
\hline Sometimes & $1726(25.5)$ & $52(24.9)$ & & & & \\
\hline Often & $2011(29.7)$ & $55(26.3)$ & & & & \\
\hline Daily & $1696(25.1)$ & $45(21.5)$ & & & & \\
\hline Vegetables (n, \%) & & & 0.090 & & & \\
\hline Never & $230(3.4 \%)$ & $11(5.3)$ & & & & \\
\hline Occasionally & $931(13.8 \%)$ & $38(18.2)$ & & & & \\
\hline Sometimes & $1519(22.4)$ & $50(23.9)$ & & & & \\
\hline Often & $1952(28.8)$ & $58(27.8)$ & & & & \\
\hline Daily & $2135(31.6)$ & $52(24.9)$ & & & & \\
\hline
\end{tabular}

Values are expressed as the means \pm SDs or $\mathrm{n}(\%)$ 


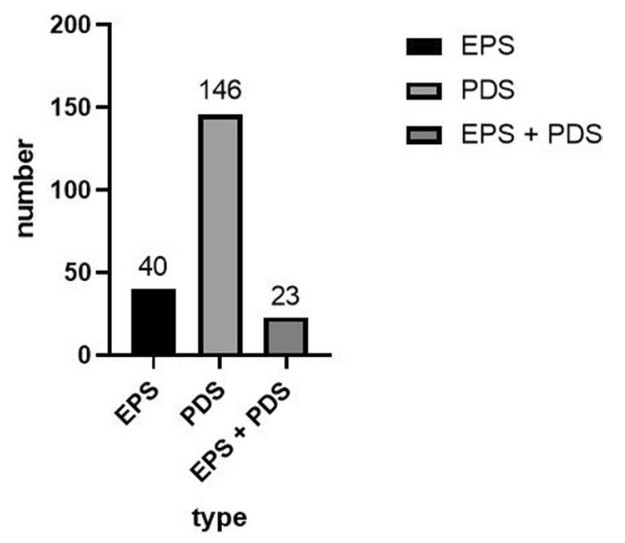

Fig. 2 Symptom subtypes of functional dyspepsia (FD) according to the Rome IV criteria. EPS epigastric pain syndrome; PDS postprandial discomfort syndrome

a diagnostic nomogram to assess FD based on the Rome IV criteria. The total score can be calculated by collecting the information of the variables on the nomogram of every Chinese children.

In our study, among the 6976 study participants, the proportion with FD was 3.0\% (209/6976) among the Chinese children. A study of FD in Japan demonstrated that after screening 2060 children using the Rome III criteria, the proportion of children who had FD was $2.8 \%$ [23]. A previous cross-sectional study involving 2136 children with functional gastrointestinal diseases showed that $2.5 \%(54 / 2136)$ of the children met the Rome III criteria for FD [24]. Among other studies of FD in children, the proportion who met the Rome III criteria for FD was between $0.9 \%$ and $16 \%$ [25-27]. Overall, the proportion of FD in our study was remarkably comparable to those of other studies.

Although a majority of patients with FD associate dyspeptic symptoms with dietary habits, studies on dietrelated factors in FD have been limited, and the results associating diet-related factors and FD are conflicting [28-31]. Wang et al. showed that cold stimulation could increase intragastric pressure in patients, elevating visceral sensitivity and reducing the gastric volume of patients. These observations were consistent with our study results that cold foods were an independent risk factors for FD [32]. In our study, children with FD were slightly older than children without, which is in line with the results of previous studies [28]. We identified that children in this population living independent of parents, who took prolonged school meals, never eat breakfast, and often eat pickled foods were more likely to have FD. However, scientific evidence for studying the efficacy of dietary and other related factors in FD is still lacking. Therefore, further well-designed studies are still needed to establish dietary risk factors related to FD.

In our study, although living independent of parents, prolonged school meals, never eat breakfast, often/daily eat cold foods, often eat pickled foods were the independent risk factors for FD, these factors had close relationship with each other. Living independent of parents was associated with bad eating habits. Children living independent of parents will largely face risk factors such

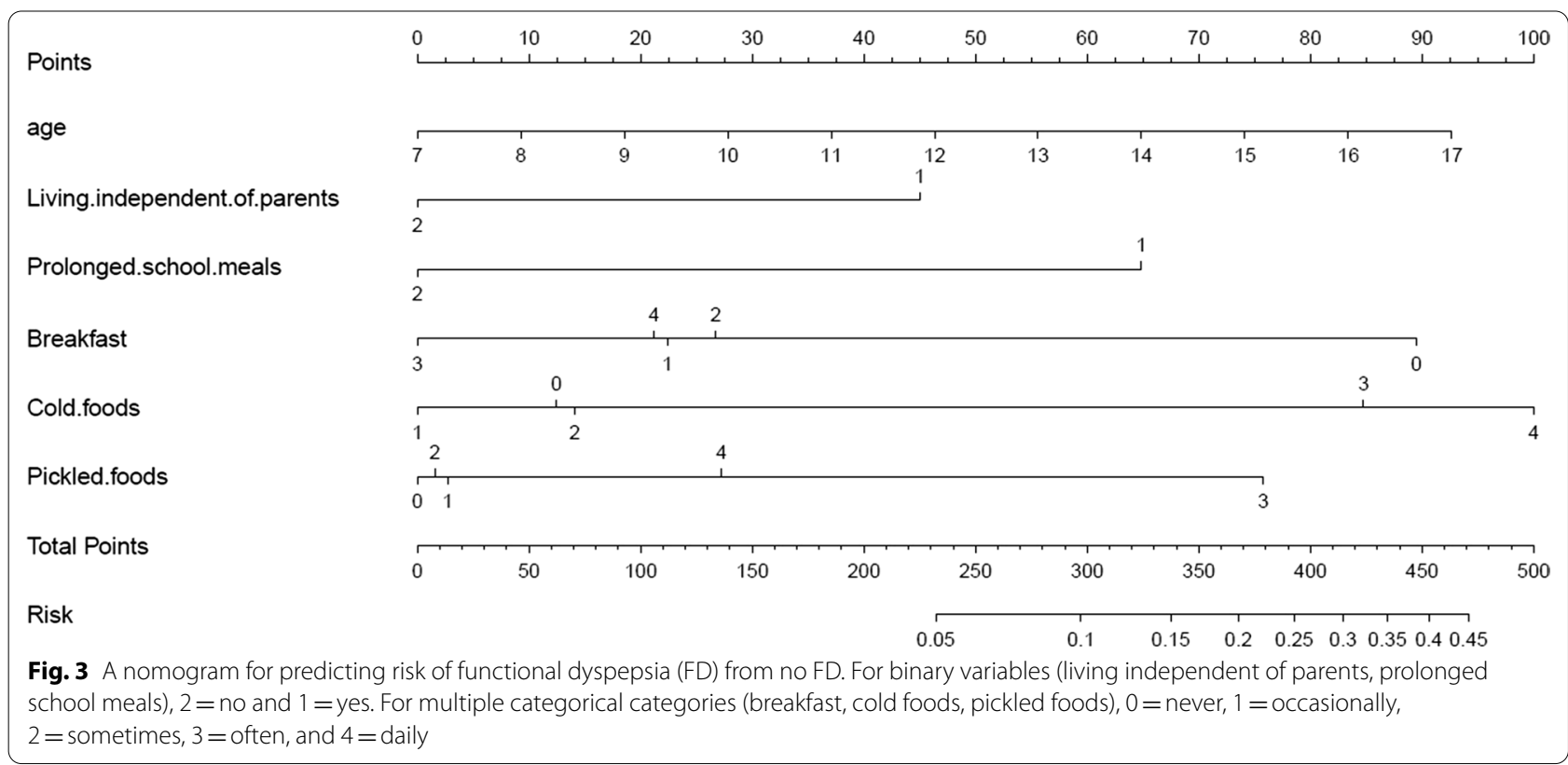




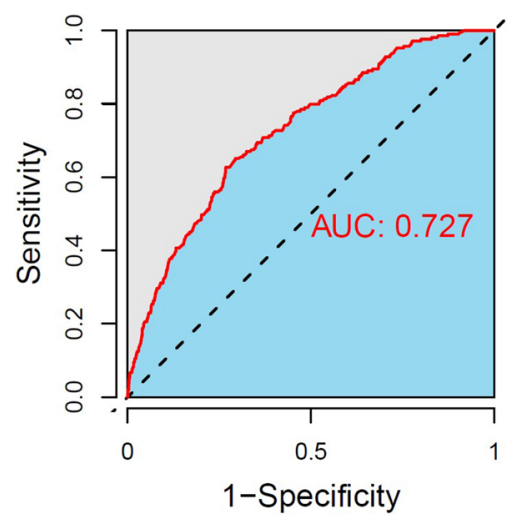

Fig. 4 ROC curves of the nomogram

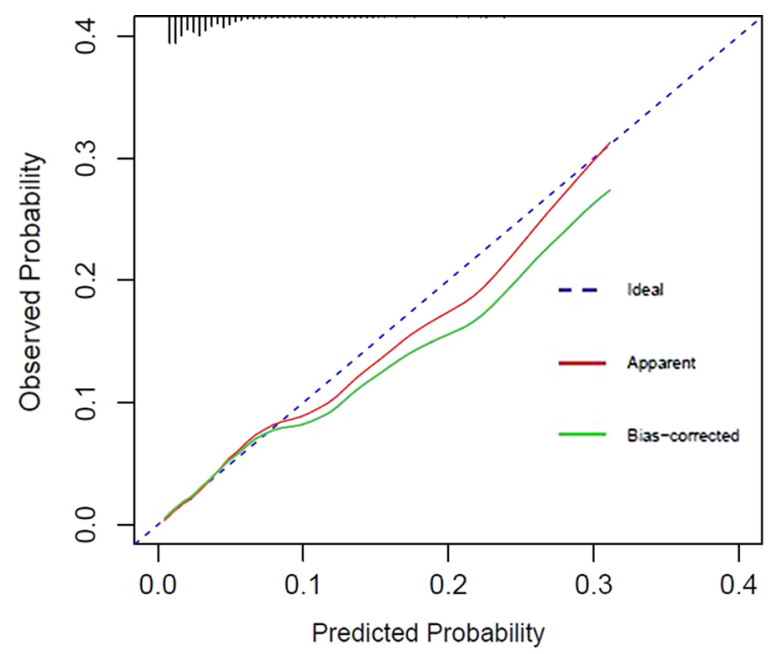

Fig. 5 Calibration curves of the nomogram

as prolonged school meals, often/daily eat cold foods, so living independent of parents was a basic and very important factor among these risk factors. In the future, more attention should be paid to children living independent of parents.

The main strength of our study is that it was a relatively large cross-sectional study designed to examine diet-related and other risk factors in Chinese children with FD based on the current Rome IV criteria. In contrast, this study also had several limitations. First, the samples in our study are all from schools in Shaanxi province and are therefore a small representation of Chinese children. There may be regional differences between our sample and other children throughout China; thus, the results of our study may not reflect the reality of the general Chinese child population, which may influence the external validity of the research results. In addition, the study population we included did not undergo gastroscopy, so we could only analyze the risk factors related to FD and could not further analyze those related to functional and organic FD.

\section{Conclusions}

Age, living independent of parents, prolonged school meals, never eat breakfast, often/daily eat cold foods, and often eat pickled foods were independent risk factors for FD in Chinese children based on the Rome IV criteria. The nomogram could be used as a quick screening tool to assess FD in Chinese children. This may contribute to the prevention and treatment options of FD.

\section{Abbreviations}

AUC: Area under the curve; BMI: Body mass index; Cl: Confidence interval; EPS: Epigastric pain syndrome; F: Female; FD: Functional dyspepsia; GI: Gastrointestinal; M: Male; PDS: Postprandial discomfort syndrome; ROC: Receiver operating characteristic.

\section{Acknowledgements}

None.

\section{Authors' contributions}

B.Q. and J.W. designed the study. Z.W., X.Y. and X.X. collected the clinical data. X.X. and L.D. performed statistical analysis. Z.W., B.Q. and J.W. wrote the manuscript. All authors finally approved the manuscript.

\section{Funding}

This work was funded by Shaanxi key research and development projects (16KTZDSF02-02). The funding source was not involved in the design of the study and collection, analysis, interpretation of data, or in writing the manuscript.

\section{Availability of data and materials}

The datasets used and/or analyzed during the current study are available from the corresponding author on reasonable request.

\section{Declarations}

\section{Ethics approval and consent to participate}

The study protocol was approved by the Ethics Committee of the Second Affiliated Hospital of Xi'an Jiaotong University (2015163). Written informed consent was obtained from school administrators and the participating

children prior to the survey.

\section{Consent for publication}

Not applicable.

\section{Competing interests}

The authors declare that they have no competing interests.

\section{Author details}

'Department of Gastroenterology, The Second Affiliated Hospital, Xi'an Jiaotong University, Xi'an, Shaanxi, China. ${ }^{2}$ Department of General Medicine, The Second Affiliated Hospital, Xi'an Jiaotong University, Xi'an, Shaanxi, China. ${ }^{3}$ Department of Cardiology, The Second Affiliated Hospital, Xi'an Jiaotong University, Xi'an, Shaanxi, China.

Received: 11 January 2021 Accepted: 3 May 2021

Published online: 12 May 2021

\section{References}

1. Talley NJ, Ford AC. Functional dyspepsia. N Engl J Med. 2015;373(19):1853-63. 
2. Ford AC, Luthra P, Tack J, et al. Efficacy of psychotropic drugs in functional dyspepsia: systematic review and meta-analysis. Gut. 2017;66(3):411-20.

3. Tack J, Camilleri M. New developments in the treatment of gastroparesis and functional dyspepsia. Curr Opin Pharmacol 2018;43:111-117

4. Ford AC, Marwaha A, Sood R, et al. Global prevalence of, and risk factors for, uninvestigated dyspepsia: a meta-analysis. Gut. 2015;64(7):1049-57.

5. Kim SE, Kim N, Lee JY, et al. Prevalence and risk factors of functional dyspepsia in health check-up population: a nationwide multicenter prospective study. J Neurogastroenterol Motil. 2018;24(4):603-13.

6. Mohamed HI, Mokarib HA, Saad ZM, et al. The prevalence of functional dyspepsia using Rome III questionnaire among chronic hepatitis $C$ patients. BMC Gastroenterol 2016;16:32.

7. Zhao Y, Zou D, Wang R, et al. Dyspepsia and irritable bowel syndrome in China: a population-based endoscopy study of prevalence and impact. Aliment Pharmacol Ther. 2010;32(4):562-72.

8. Miwa $\mathrm{H}$, Oshima T, Tomita T, et al. Recent understanding of the pathophysiology of functional dyspepsia: role of the duodenum as the pathogenic center. J Gastroenterol. 2019;54(4):305-11.

9. Aro $P$, Talley NJ, Agréus L, et al. Functional dyspepsia impairs quality of life in the adult population. Aliment Pharmacol Ther. 2011:33(11):1215-24.

10. Madisch A, Andresen $V$, Enck $P$, et al. The diagnosis and treatment of functional dyspepsia. Deutsches Arzteblatt international. 2018;115(13):222-32.

11. Mahadeva S, Yadav H, Rampal S, et al. Risk factors associated with dyspepsia in a rural Asian population and its impact on quality of life. Am J Gastroenterol. 2010;105(4):904-12.

12. Akhondi-Meybodi M, Aghaei MA, Hashemian Z. The role of diet in the management of non-ulcer dyspepsia. Middle East J Dig Dis. 2015;7(1):19-24.

13. Duncanson KR, Talley NJ, Walker MM, et al. Food and functional dyspepsia: a systematic review. J Hum Nutr Diet. 2018;31(3):390-407.

14. Ansari S, Ford AC. Initial management of dyspepsia in primary care: an evidence-based approach. Br J Gen Pract. 2013;63(614):498-9.

15. Hyams JS, Di Lorenzo C, Saps M, et al. Functional disorders: children and adolescents. Gastroenterology (2016).

16. Rasquin A, Di Lorenzo C, Forbes D, et al. Childhood functional gastrointestinal disorders: child/adolescent. Gastroenterology. 2006;130(5):1527-37.

17. Saps M, Velasco-Benitez CA, Langshaw AH, et al. Prevalence of functional gastrointestinal disorders in children and adolescents: comparison between Rome III and Rome IV criteria. J Pediatr 2018;199:212-216.

18. Drossman DA. Functional Gastrointestinal Disorders: History, Pathophysiology, Clinical Features and Rome IV. Gastroenterology (2016).

19. Talagala Ishanka A, Arambepola C. Use of food labels by adolescents to make healthier choices on snacks: a cross-sectional study from Sri Lanka. BMC Public Health 2016:16:739.
20. Tack J, Masuy I, Van Den Houte K, et al. Drugs under development for the treatment of functional dyspepsia and related disorders. Expert Opin Investig Drugs. 2019;28(10):871-89.

21. Wauters L, Talley NJ, Walker MM, et al. Novel concepts in the pathophysiology and treatment of functional dyspepsia. Gut (2019).

22. Masuy I, Van Oudenhove L, Tack J. Review article: treatment options for functional dyspepsia. Aliment Pharmacol Ther. 2019;49(9):1134-72.

23. Kumagai H, Yokoyama K, Imagawa $T$, et al. Functional dyspepsia and irritable bowel syndrome in teenagers: Internet survey. Pediatr Int. 2016;58(8):714-20.

24. Devanarayana NM, Mettananda S, Liyanarachchi C, et al. Abdominal pain-predominant functional gastrointestinal diseases in children and adolescents: prevalence, symptomatology, and association with emotional stress. J Pediatr Gastroenterol Nutr. 2011;53(6):659-65.

25. Sagawa T, Okamura S, Kakizaki S, et al. Functional gastrointestinal disorders in adolescents and quality of school life. J Gastroenterol Hepatol. 2013;28(2):285-90.

26. Carbone F, Tack J, Hoffman I. The intragastric pressure measurement: a novel method to assess gastric accommodation in functional dyspepsia children. J Pediatr Gastroenterol Nutr. 2017:64(6):918-24.

27. Ganesh M, Nurko S. Functional dyspepsia in children. Pediatr Ann. 2014;43(4):e101-105.

28. Carvalho RV, Lorena SL, Almeida JR, et al. Food intolerance, diet composition, and eating patterns in functional dyspepsia patients. Dig Dis Sci. 2010;55(1):60-5.

29. Feinle-Bisset C, Vozzo R, Horowitz M, et al. Diet, food intake, and disturbed physiology in the pathogenesis of symptoms in functional dyspepsia. Am J Gastroenterol. 2004;99(1):170-81.

30. Tan VP. The low-FODMAP diet in the management of functional dyspepsia in East and Southeast Asia. J Gastroenterol Hepatol 2017;46-52.

31. Cuperus P, Keeling PW, Gibney MJ. Eating patterns in functional dyspepsia: a case control study. Eur J Clin Nutr. 1996;50(8):520-3.

32. Wang RF, Wang ZF, Ke MY, et al. Temperature can influence gastric accommodation and sensitivity in functional dyspepsia with epigastric pain syndrome. Dig Dis Sci. 2013;58(9):2550-5.

\section{Publisher's Note}

Springer Nature remains neutral with regard to jurisdictional claims in published maps and institutional affiliations.

Ready to submit your research? Choose BMC and benefit from:

- fast, convenient online submission

- thorough peer review by experienced researchers in your field

- rapid publication on acceptance

- support for research data, including large and complex data types

- gold Open Access which fosters wider collaboration and increased citations

- maximum visibility for your research: over 100M website views per year

At BMC, research is always in progress.

Learn more biomedcentral.com/submissions 